\title{
The paediatrician and the rabbi
}

Avinoam Shuper, Avraham Zeharia, Judy Balter-Seri, David Steier, Marc Mimouni Schneider Children's Medical Center of Israel, Petah Tiqva, and Tel Aviv University, Tel Aviv, Israel

\begin{abstract}
Objectives-During recent decades, rabbis in Israel have been playing an increasing role in the consultation of patients or their families on medical issues. The study was performed to determine the attitude of physicians to rabbinical consultation by parents of sick children for purposes of basic medical decision making.

Design and setting-A questionnaire was prepared which contained questions regarding physicians' reactions to specific medical situations as well as their demographic data. The study participants included all the available physicians who were employed in the study period at one tertiary medical centre in Israel, which is not associated with any religious organisation. The questionnaire was presented personally to all of the physicians who were available for the study. Results-Between $63 \%$ and $77 \%$ of the respondents were accepting of rabbinical consultation in regard to medical decisions. Nevertheless, in cases of divergence from accepted medical practice and in emergencies, almost all stated they would take measures to resist the rabbi's advice. This attitude did not correlate with the physician's age, religious status or experience in medicine.

Conclusions-Israeli physicians respect rabbis' suggestions in the area of medical decision making, though they would not let a rabbi's advice interfere with their decisions if they believed the rabbi's opinion went against medical need. In order to prevent an untoward effect of the rabbinical involvement in medicine, rules should be set to establish norms for rabbi-physician collaboration.

(Fournal of Medical Ethics 2000;26:441-443)
\end{abstract}

Keywords: Medical decisions; rabbinic involvement; conventional medicine

\section{Introduction}

Seeking out the chaplain for comfort or moral support when conventional medicine fails, for instance near the time of death of a patient, is common practice worldwide, and many care facilities now include chaplains on the medical team for this purpose. ${ }^{1-3}$ In Israel, however, for decades we have witnessed a unique phenomenon wherein rabbis, usually from the ultraorthodox stream, are actively consulted by patients or their families, for help in making basic medical decisions in the acute care of emerging problems, such as which physician, hospital, or treatment should be chosen for a specific disorder. Rabbis' advice is not sought in regard to the moral, ethical or spiritual appropriate- ness of a specific testing or treatment for particular conditions but in regard to the appropriateness of medical-professional decisions. Rarely, a rabbi will interpret test results, perhaps of an imaging study, or express an opinion about a specific treatment that has been recommended. Most questions involve the more serious oncological diseases or major surgical procedures, but minor problems may be addressed as well. This trend has been observed among both religious and secular Jews and even in the Arab population. To the best of our knowledge, all the rabbis involved in this type of consultation belong to the Jewish Orthodox segment of Judaism. The role of the rabbi in the medical world in Israel gained popular recognition when the most prominent among them, Rabbi Elimelech Firer, received the much coveted Israel National Prize for his activities.

With the change in the rabbi's place in medicine, the rabbinic and medical worlds are expected to have mutual respect and to work together. Physicians would probably like to be recommended by the rabbi, and through his recommendations or referrals, the rabbi may gain substantial influence on all the activities within particular departments. The aim of the present study was to assess physicians' attitudes towards the increasing intervention of the rabbi in medical activities and the influence it has on their work.

\section{Methods}

A questionnaire was prepared (summarised in tables 1 and 2) which contained questions regarding the physician's attitude towards rabbinical consultation by parents of sick children in regard to proper medical decisions, in different medical situations. Also there were questions regarding their reactions to the rabbi, and requests for suggestions in cases where the physicians did not agree with them. All available physicians who were employed in the study period in the Schneider Children's Medical Center of Israel, which is a major tertiary referral facility, unrelated to any religious organisation, were included. The questionnaire was presented to each physician personally. Medical students were not included. Statistical analysis was performed with the BMDP Statistical Software package (1990). ${ }^{4}$

\section{Results}

One hundred and thirteen physicians with varying experience, all specialising in paediatrics, were interviewed. The characteristics of the respondents 
Table 1 Characteristics of responding physicians

\begin{tabular}{lc}
\hline Characteristics & $\begin{array}{l}\text { No of } \\
\text { Physicians (\%) }\end{array}$ \\
\hline Age range (yr) & $55(48.7)$ \\
$20-40$ & $39(34.8)$ \\
$41-50$ & $18(15.9)$ \\
$>51$ & $6(5.3)$ \\
Religious & $22(19.5)$ \\
$\quad$ Orthodox & $82(72.6)$ \\
Traditional & \\
Non-religious & $44(38.9)$ \\
Medical experience (yr) & $38(33.6)$ \\
$\quad<10$ & $27(23.9)$ \\
$11-20$ & $36(31.9)$ \\
$>21$ & $34(30.5)$ \\
Training & $42(37.6)$ \\
$\quad$ Resident & \\
Certified in paediatrics & \\
Paediatric subspecialty &
\end{tabular}

${ }^{\star}$ Jewish

are shown in table 1. The data analysis included only the questions to which specific responses were received. The physicians' attitudes towards different medical situations is summarised in table 2 . No less than $63 \%$ of the physicians said they would be open to rabbinical consultation, even for the performance of an emergency test, such as a spinal tap. Overall, the involvement of the rabbi in medica decisions was considered unwarranted by 25 physicians $(22.1 \%)$, acceptable by $68(60.1 \%)$ and desirable by $13(11.5 \%)$. Thirty-nine physicians $(34.5 \%)$ said they would be ready to give the rabbi a position as a partner in the care of the child in a discussion of a medical issue regarding individual patients, and $21(18.6 \%)$ said they themselves would consult a rabbi for a significant personal medical problem.

No correlation was found between any of the physicians' characteristics (table 1) and their attitudes to rabbinic involvement in medical decisions.

\section{Conclusion}

The freedom to act within the dictates or spirit of one's faith is a well recognised right in developed countries and influences all areas of life, including health care. ${ }^{5}$ For example, religious beliefs may lead some individuals to request treatment that seems inappropriate on a medical basis. ${ }^{6}$ Rabbis are often consulted in the process of coping with medical problems. Several studies to date have addressed the role of religious advisors in psychotherapy and end-of-life care. Rabbis are frequently called upon for advice about genetic counselling ${ }^{7}$ though one survey found that most rabbis feel poorly prepared in this area. ${ }^{8}$ In the present study, we evaluated physicians' reactions towards the increasingly expanding role of the chaplain in Israeli medicine. Rabbis are having an increasing influence on patients' and/or their families' medical decision making. As a direct effect of this, rabbis have gone from being complementary to conventional medicine to being an integral and active part of it. Some rabbis have acquired the knowledge and facilities to advise patients on which procedures to undergo by which physicians. They keep abreast of innovations worldwide and have close connections with professional, medical information sources. In some cases they duplicate medical material and transport it abroad to specific centres. It should be stressed that rabbis give their opinion only at the specific request of the patient, and mostly they do not profit from these activities.

The present study clearly shows that parental consultation with a rabbi on medical issues is widely accepted by paediatricians working in a tertiary hospital in Israel. For all medical situations described, no less than two-thirds of the paediatricians accepted the rabbi as a legitimate partner in the care of the child. Nevertheless, this acceptance as a partner does not necessarily mean agreement with, or following of, the rabbi's advice. The lowest acceptance rates were noted for emergencies, where slightly more than one-third of physicians objected to the rabbi's role. In cases of a conflict between the rabbi's advice and medical need, as determined by the physician, only a negligible number of respondents would follow the rabbi's recommendations. However, one-fourth believed it appropriate to contact the rabbi in these cases, to discuss the reasons for his reservations.

It is noteworthy that we found no correlation between any of the physician characteristics studied and the attitude of physicians towards rabbinic intervention in medical decision making. We found

Table 2 Physician responses regarding rabbinic involvement in different medical situations

\begin{tabular}{|c|c|c|c|c|c|c|c|c|}
\hline \multirow[b]{2}{*}{ Areas rabbis' advice requested } & \multicolumn{4}{|c|}{ Physicians'responses } & \multicolumn{4}{|c|}{ Physician actions when disagrees with rabbi } \\
\hline & Object & Accept & Encourage & Unknown* & $\begin{array}{l}\text { Confront } \\
\text { parents }\end{array}$ & Call rabbi & $\begin{array}{l}\text { Follow } \\
\text { rabbi's } \\
\text { advice }\end{array}$ & Unknown* \\
\hline Non-invasive test (ie, $\mathrm{x}$-ray) & $31(27.4)$ & $77(68.1)$ & $5(4.4)$ & 0 & $65(57.5)$ & $30(26.5)$ & $4(3.5)$ & $14(12.4)$ \\
\hline Non-emergency invasive test & $8(7.1)$ & $92(81.5)$ & $11(9.7)$ & $2(1.8)$ & $48(42.4)$ & $53(46.9)$ & $2(1.8)$ & $10(8.8)$ \\
\hline $\begin{array}{l}\text { Emergency invasive test (ie, } \\
\text { LP) }\end{array}$ & $38(33.6)$ & $63(55.7)$ & $9(8.0)$ & $3(2.7)$ & $6(58.4)$ & $35(31.0)$ & $0(0)$ & $12(10.6)$ \\
\hline $\begin{array}{l}\text { Non-routine treatment (ie, } \\
\text { IVIG) }\end{array}$ & 21 (18.6) & $77(68.1)$ & $0(8.0)$ & $6(5.3)$ & 46 (49.5) & $44(38.9)$ & $1(0.9)$ & $12(10.6)$ \\
\hline Second opinion & $17(15.0)$ & $82(72.6)$ & $9(8.0)$ & $5(4.4)$ & $26(23.0)$ & $20(17.70)$ & $37(32.7)$ & $30(26.5)$ \\
\hline
\end{tabular}

* covers those who did not answer a particular question.

Figures in brackets are percentages. 
no significant difference between the attitudes of Orthodox and secular physicians. Presumably, physicians can strictly differentiate between their religious beliefs and concepts and their professional work. Earlier studies have reported a relationship between physicians' medical experience and specialty and their decisions to withdraw life support. Although the situations in the present study are not comparable, a positive attitude towards rabbinical involvement could be expected to correlate with older age or greater experience in medicine, but this was not the case. We speculate that physicians' training today may increase their understanding of patients' need for outside support in their medical decisions.

The present survey was addressed to physicians in a single institution in Israel, though a very central and significant one. Further studies are needed to determine whether these results can be generalised to other institutions in Israel or more broadly, to Jewish and non-Jewish physicians and communities elsewhere. Moreover, the questions raised may be relevant also to other non-medical advisors involved in medical decision making. It should be noted that we have no information about similar controversies in Catholic or Muslim communities.

In conclusion, paediatricians in a tertiary hospital are accepting of rabbinic involvement in conventional medicine, though they do not allow it to interfere with their work in cases where there is serious disagreement. Though such consultation may be reassuring to patients and acceptable to doctors, its growing use raises several fundamental questions: Should rabbinical intervention in medical decisions be allowed at all? Should it be encouraged? Does high rabbinic involvement in medicine in the long run lead to inappropriate treatment in some cases? May it lead to inappropriate rabbiphysician relationships? We suggest that guidelines be established setting norms for such collaboration in order that unwarranted results will not affect medical decisions. Such norms should relate to the limits of professional interrelationships between a rabbi and a medical institution or a single physician, possible mutual benefits, delivery of medical information, and appropriate registration of rabbinic involvement and its outcome.

Avinoam Shuper, Avraham Zeharia, fudy Balter-Seri, David Steier and Marc Mimouni work in the Department of Pediatrics E, Schneider Children's Medical Center of Israel, Petah Tiqva, and Sackler Faculty of Medicine, Tel Aviv University, Tel Aviv, Israel.

\section{References}

1 Wallace AC, Jackson S. Establishing a district palliative care team for children. Child Care Health Development 1995;21:3835.

2 Sharp CG. Use of chaplaincy in the neonatal intensive care unit. Southern Medical fournal 1991;84:1482-6.

3 Wanger JT, Higolan TL. Spiritual issues and bioethics in the intensive care unit: the role of the chaplain. Critical Care Clinics 1996;12:15-27.

4 Dixon WJ, ed. BMDP statistical software. Los Angeles: University of California Press, 1990.

5 Trappler B, Greenberg S, Friedman S. Treatment of Hassidic Jewish patients in a general hospital medical-psychiatric unit.

6 Orr RD, Genesen LB. Requests for "inappropriate" treatment Orr RD, Genesen LB. Requests for "inappropriate" treatment $142-7$.

7 Steiner-Grossman P, David KL. Involvement of rabbis in counseling and referral for genetic conditions: results of a survey. American fournal of Human Genetics 1993;53:1359-65.

8 Brown J. Prenatal screening in Jewish law. fournal of Medical Ethics 1990;16:75-80

9 Christakis NA, Asch DA. Physicians' characteristics associated with decisions to withdraw life support. American fournal of Public Health 1995;85:367-72.

\section{News and notes \\ 6th European Forum on Quality Improvement in Health Care}

The 6th European Forum on Quality Improvement in Health Care will be held from Thursday 29 March to Saturday 31 March 2001 in Bologna, Italy.

For full information contact: BMA/BMJ Conference
Unit, BMA House, Tavistock Square, London WC1H 9JP, UK. Tel: +44 (0) 207383 6409; fax: + 44 (0) 207 383 6869; email: Quality@bma.org.uk. Bookmark the web site for full information: www.quality.bmjpg.com 